\title{
Stereotactic Management of Bacterial Brain Abscesses
}

\author{
Sohrab Shahzadi, Andres M. Lozano, Mark Bernstein, \\ Abhijit Guha and Ronald R. Tasker
}

\begin{abstract}
Background: CT and MR guided stereotactic techniques have provided promising results in the management of brain abscesses. We reviewed our results of stereotactic management of brain abscesses in 20 consecutive patients with 28 abscesses from 1986 to 1993. Methods: 13 abscesses were in the cerebral hemispheres, 12 in the cerebellum, 2 in the pons and 1 in the thalamus. The bacterial organism was isolated in 12 of the 20 cases. All patients, except one who had a tuberculous abscess, were on antibiotics for less than 7 weeks. Results: Although there were 3 patients in coma before surgery, the mortality rate was zero and 17 patients had an excellent recovery with 3 patients having a persistent mild neurologic disability. Stereotactic aspiration of the largest lesion in the patients with multiple brain abscesses combined with intravenous antibiotic therapy was sufficient for the resolution of all lesions. Two of our patients treated with antibiotics alone showed abscess progression with neurologic worsening. Conclusion: Stereotactic aspiration is safe, accurate, and when combined with the appropriate antibiotics, should be considered the procedure of choice in the management of brain abscesses.
\end{abstract}

RÉSUMÉ: Traitement par stéréotaxie des abcès cérébraux bactériens. Introduction: Les techniques stéréotaxiques guidées par CT et MR offrent des résultats prometteurs dans le traitement des abcès cérébraux. Nous avons révisé les résultats du traitement stéréotaxique des abcès cérébraux chez 20 patients consécutifs avec 28 abcès, de 1986 à 1993. Méthodes: 13 abcès étaient situés dans les hémisphères cérébraux, 12 dans le cervelet, 2 dans le pont et 1 dans le thalamus. L'organisme pathogène a été isolé dans 12 des 20 cas. Tous les patients sauf un, qui avait un abcès tuberculeux, ont pris des antibiotiques pendant moins de 7 semaines. Résultats: Bien que 3 patients étaient dans le coma avant la chirurgie, le taux de mortalité a été nul, 17 patients ont eu une excellente récupération et 3 patients ont présenté des séquelles neurologiques légères. L'aspiration stéréotaxique de la plus grosse lésion chez les patients avec des abcès cérébraux multiples combinée à l'antibiothérapie intraveineuse a été suffisante pour induire la résolution de toutes les lésions. Deux de nos patients traités par antibiothérapie seulement ont eu une progression de leur lésion avec détérioration neurologique. Conclusions: L'aspiration stéréotaxique est sécuritaire, précise et, quand elle est combinée à l'antibiothérapie appropriée, devrait être considérée comme l'intervention de choix dans le traitement des abcès cérébraux.

Can. J. Neurol. Sci. 1996; 23: 34-39

The management of bacterial brain abscesses is a subject of controversy in neurosurgery. Among the treatments proposed are antibiotics alone ${ }^{1}$ or in combination with aspiration, ${ }^{2}$ aspiration with instillation of antibiotics ${ }^{3}$ and craniotomy for excision. ${ }^{4}$ Certain reports conclude that antibiotic therapy alone can cure large brain abscesses ${ }^{5-7}$ while others emphasize that surgery is necessary. ${ }^{8-9}$

The mortality rate from brain abscesses has remained high through the early 1970 s with reported figures of $40-50 \% .{ }^{10-14}$ However in the past two decades there has been significant improvement in case management with some authors reporting a mortality rate of zero. ${ }^{15-17}$ This improved outcome can be attributed to a number of factors including earlier diagnosis, ${ }^{18-23}$ improved bacteriological isolation, ${ }^{24-25}$ better antibiotics ${ }^{26-28}$ and better surgical procedures. ${ }^{29-31}$

Stereotactic aspiration of brain abscesses offers many advantages and in recent reports appears to offer good results with low surgical morbidity and mortality. ${ }^{32-35}$ We have utilized the techniques of stereotactic aspiration to treat 20 patients with brain abscesses. This report outlines the presentation, treatment and

From the Division of Neurosurgery. The Toronto Hospital, University of Toronto, Toronto.

RECEIVED APRIL 11, 1995. ACCEPTED IN FINAL FORM SEPTEMBER 11, 1995.

Reprint requests to: Andres M. Lozano, M.D., Division of Neurosurgery, The Toronto Hospital, University of Toronto, Suite 2-433, 399 Bathurst Street, Toronto, Ontario, Canada M5T 2S8 
outcome of a large group of patients treated by stereotactic aspiration and antibiotics.

\section{Methods}

Between 1986 - 1993, 20 consecutive patients with 28 brain abscesses were treated surgically. In 19 patients, stereotactic treatment was the only modality used. One patient had a craniotomy and drainage followed by abscess re-accumulation which was treated stereotactically. There were 14 males and 6 females. The ages ranged from 19-75 years (Table 1).

Signs of increased intracranial pressure were the commonest feature with 18 of 20 patients $(90 \%)$ presenting with headaches, vomiting or papilloedema. Fever was present in $7(35 \%)$ and meningeal irritation in only 4 (20\% of cases). There were 3 patients with Glasgow Coma Scales of 7 or lower. Hemiparesis was present in 7 patients (35\%). Speech disturbance and hemianopsia occurred in $5(25 \%)$ and $4(20 \%)$ respectively and nystagmus or ataxia in $3(15 \%)$. Seizures were presenting symptoms in 2 patients (10\% of total patients, $14 \%$ of those with cerebral lesions). Symptoms were present four days to six weeks prior to diagnosis.

In all patients, a search was made for predisposing factors. Three patients had a middle ear infection. Two patients had concomitant dental abscesses. In two cases abscesses resulted as complications of intracranial surgical procedures. One patient had bronchitis and in two the abscesses developed after trauma. One patient was a heavy alcohol user and had liver failure. No predisposing factors could be found in the remaining nine patients. No patient was seropositive for the human immunodeficiency virus.

Table 1: Patients with Brain Abscesses. Patient data: age, sex, site, organisms, source, medications, duration (zero being the day of surgery - pre-op and + post-op), outcome (glasgow outcome scale) and follow up.

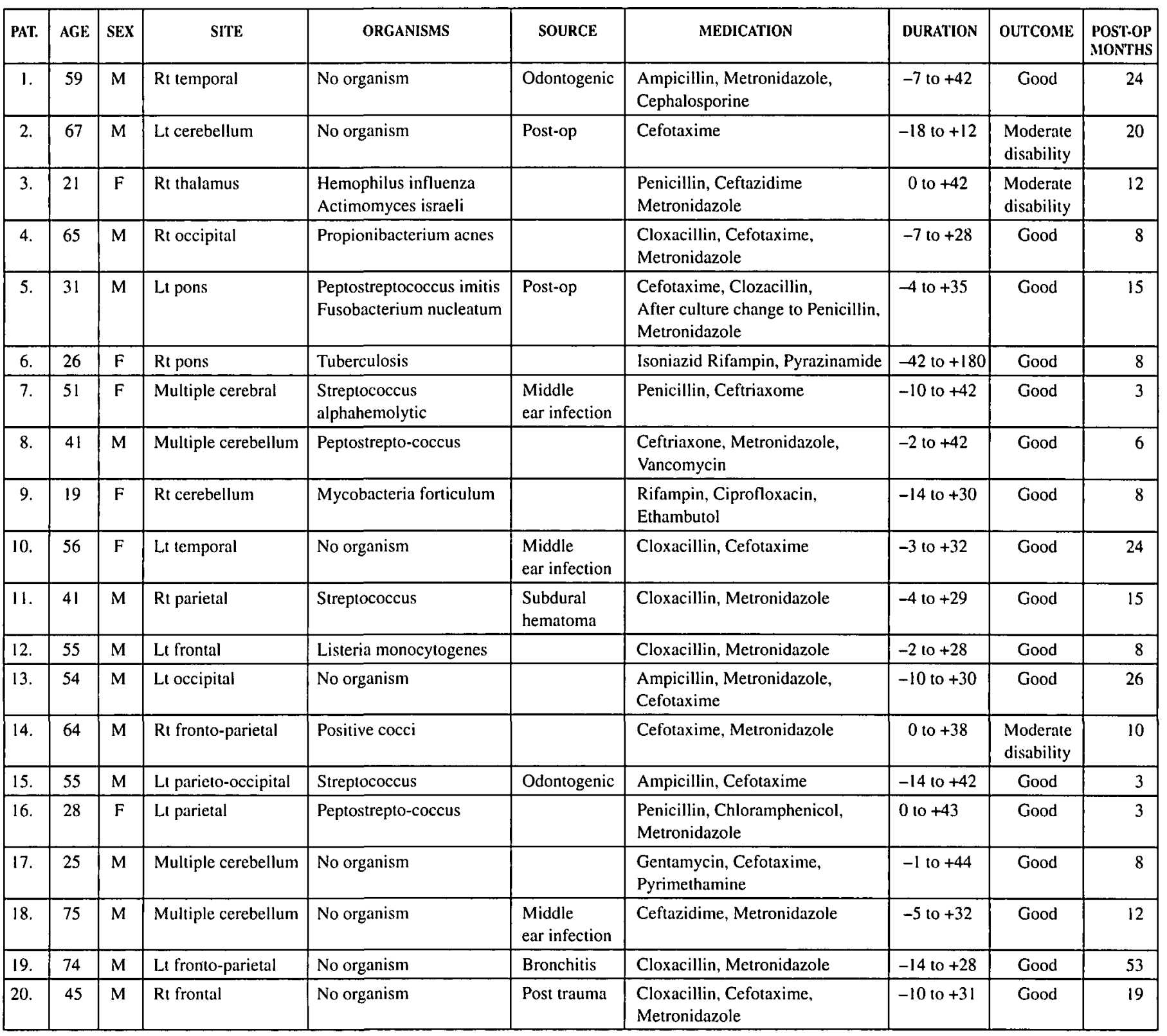




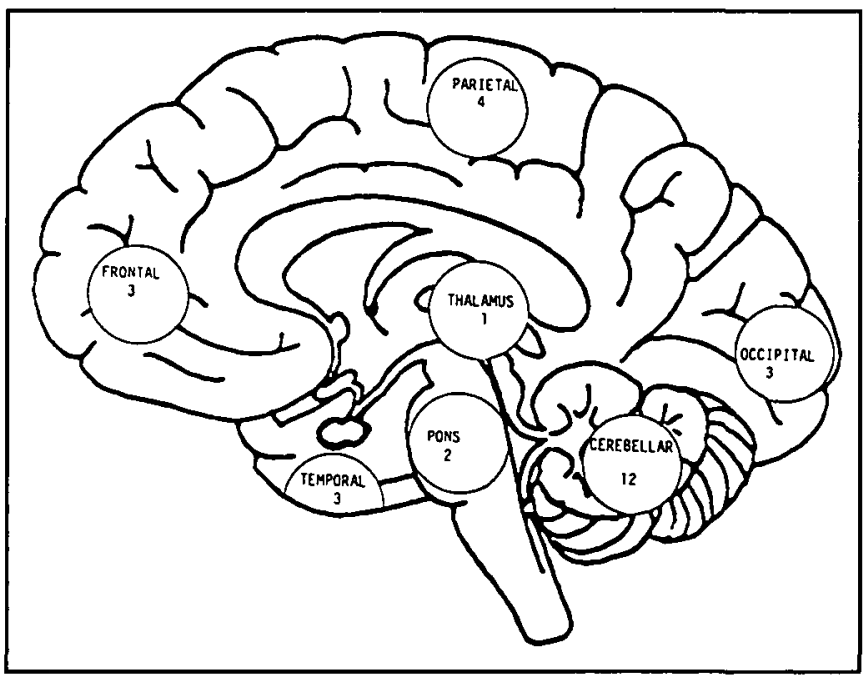

Figure 1: Location of 28 brain abscesses in 20 patients.

\section{RESULTS}

\section{Indications}

Stereotactic aspiration in this consecutive patient series was done for any lesion that had the imaging features of brain abscess. There were no false positive diagnoses of abscesses in this study.

\section{Location}

There were two abscesses in the pons, one in the thalamus, 12 in the depth of the cerebellum and posterior fossa and 13 in the cerebral hemispheres. The location of the brain abscesses is shown in Figure 1.

\section{Multiple Brain Abscesses}

There were four patients with multiple brain abscesses in this series (patients 7, 8, 17 and 18 in Table 1 had 2, 4, 2 and 4 respectively). Only the largest and most symptomatic abscess was aspirated in each case.

\section{Surgery}

Stereotactic procedures were performed with the BrownRoberts-Wells (BRW) or Leksell stereotactic systems by four surgeons, using local anaesthesia in 19 patients and under general anaesthesia in one obtunded patient (patient 3, Table 1). Intravenous contrast enhanced CT scans were performed with 1.5-3 $\mathrm{mm}$ thick slices to localize the best target. The skull was perforated by a twist drill hole and a side opening biopsy needle directed through the abscess wall and then to the centre of the abscess cavity. Trajectories were chosen to avoid ventricles, cisterns and eloquent brain areas.

All patients were given dexamethasone and anti-convulsant drugs prior to surgery. Aspiration was performed using a $10 \mathrm{ml}$ syringe applying $1 \mathrm{ml}$ of suction. Specimens were submitted for pathological and microbiological examinations including Gram stains and cultures for aerobic and anaerobic bacteria and for fungi. The volume of purulent material drained varied from 3$20 \mathrm{ml}$; purulent material was obtained in all 20 patients. The abscess diameters as measured on CT scans, varied from 1-4.3 $\mathrm{cm}$ which allowed estimation of abscess volume. A microbiological diagnosis was obtained in 12 of 20 patients (Table 1).
All but one patient who had a tuberculous abscess were on antibiotics for less than seven weeks. Postoperative CT scans were obtained within 24 hours of surgery and every 7-12 days until the time of discharge. One patient had 2 repeat aspirations for what appeared to be abscess recurrence (patient 11, Table 1). Each repeat aspiration however yielded negative cultures. After four weeks of antibiotics, there was complete radiological resolution of the abscess in this patient.

There were no surgical complications and no recurrences of abscesses after cessation of the antibiotics. In this series however, we documented two clear cut cases of progression of abscesses treated elsewhere with antibiotics alone (patients 8 and 13, Table 1). One example (patient 13) is shown in Figure 2. This observation reinforces the need to identify the causative organism and drain the infected material.

\section{Discussion}

The treatment of brain abscesses depends on eliminating the infectious process and reducing the mass effect caused both by the necrosis of brain tissue, the inflammatory suppurative response and the surrounding cerebral edema. ${ }^{4.8}$

Heinenman et al. ${ }^{7}$ in 1971 introduced the concept of nonsurgical management of brain abscesses using only antibiotics without direct bacteriologic examination leading a number of investigators to report cures with the use of antibiotics with or without corticosteroids. ${ }^{36.37}$ The antibiotics of choice for initial treatment or for the management of culture negative bacterial brain abscesses are penicillin and metronidazole for abscesses arising from the perinasal sinuses, penicillin, metronidazole and a third generation cephalosporin for abscesses secondary to otitis media or for those originating through hematogenous spread. ${ }^{38}$ For abscesses secondary to penetrating trauma, cloxacillin with penicillin and metronidazole have been advocated while for post neurosurgical procedure abscesses vancomycin has been suggested..$^{38}$

Drainage of the infected material has several theoretical advantages. ${ }^{2}$ The number of organism can be reduced and the abscess cavity can shrink in size, decreasing mass effect and allowing better penetration of antibiotics from the vascularized abscess capsule. ${ }^{28}$ Aspiration also permits the identification of the causative organism and allows the best possible choice of antibiotics. ${ }^{26.28}$ In addition, the diminution of infected material with aspiration also has the potential for reducing the magnitude of the brain inflammatory response and reactive edema which also may be of benefit. ${ }^{2}$ These factors coupled with the low morbidity and mortality of stereotactic drainage as documented in our series and the risk of abscess enlargement with antibiotic treatment alone argue for the immediate stereotactic drainage of these lesions. ${ }^{39}$

The use of stereotaxy enables the surgeon to reach small and deep brain lesions with minimal risk to surrounding structures. ${ }^{40-43}$ Stereotactic procedures also allow selection of the trajectory that minimizes the risk of traversing and seeding the ventricles or cisterns. ${ }^{44}$ Although we did not find it necessary in the series, multiple lesions can be treated in a single setting. ${ }^{45}$ Moreover, severely ill patients who are poor candidates for craniotomy under general anaesthesia can be treated effectively by stereotaxy with local anaesthesia. ${ }^{46}$ 

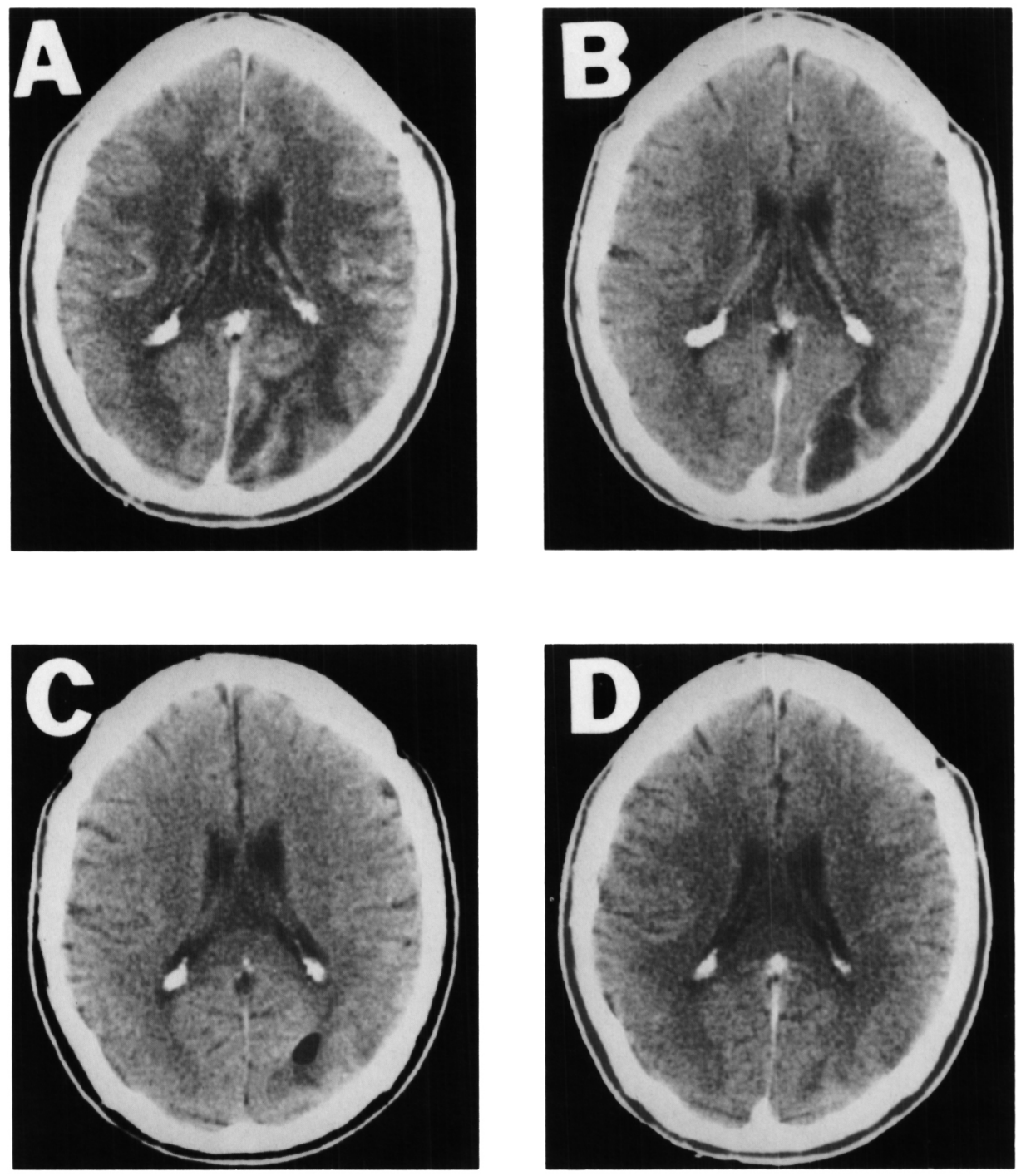

Figure 2: CT scan of a 54 year old man (patient 13, Table I) with a left occipital abscess: (A) the abscess before treatment. (B) abscess progression with antibiotic therapy alone for 13 days. (C) abscess after drainage by stereotactic aspiration. and (D) complete disappearance after 26 days antibiotic therapy.

Table 2: Result of stereotactic aspiration of brain abscesses in some reported series.

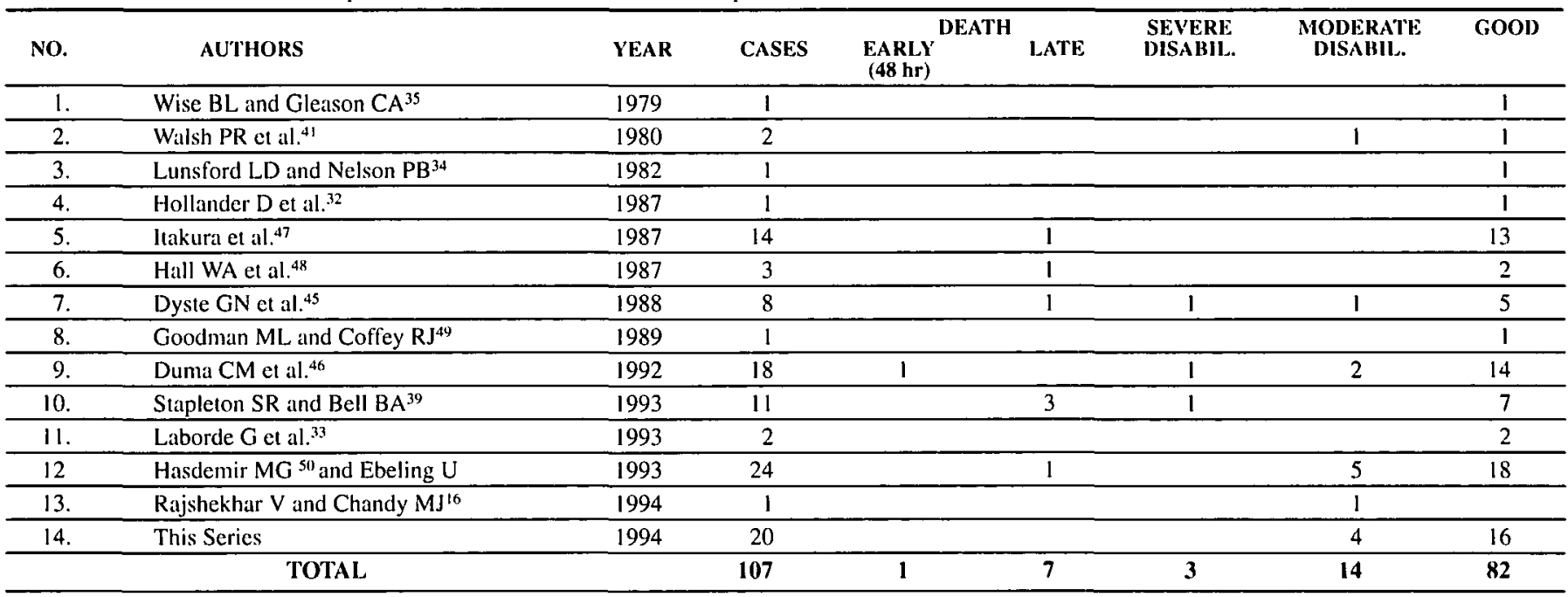

Outcomes: severe disability, moderate disability or good. 
The use of CT guided stereotactic techniques in the treatment of brain abscesses has been previously reported to show good results with low surgical morbidity and mortality. Several stereotactic series report morbidity and mortality rates of $1-8 \%$ (Table 2). Although no direct measures of morbidity and mortality with open craniotomy are available, the latter would be expected to be associated with a significantly higher risk and also a longer hospital stay and higher cost.

The results of this series show that brain abscesses can be treated effectively and safely by a combination of stereotaxy and antibiotics. In the vast majority of patients, the stereotactic procedure can be performed under local anaesthesia to rapidly and effectively drain the purulent process, obtain a bacteriologic diagnosis allowing the choice of the most appropriate chemotherapeutic agent. All patients treated in this fashion had complete resolution of their infective process. There were no surgical complications in this series. Two patients treated with antibiotics alone prior to being referred to our centre showed abscess enlargement with clinical deterioration. This observation underscores the importance surgical treatment, accurate diagnosis and tailoring the chemotherapeutic agents to the causative organisms. Because of its safety and effectiveness we favour stereotactic aspiration with antibiotic therapy as the treatment of choice in the management of brain abscesses.

\section{REFERENCES}

1. Boom WH, Tuazon CU. Successful treatment of multiple brain abscesses with antibiotics alone. Rev Infect Dis 1985; 7: 189199.

2. Stephanov S, Joubert MJ. Large brain abscesses treated by aspiration alone. Surg Neurol 1982; 17: 339-340.

3. Broggi G, Franzini A, Peluchetti D, Servello D. Treatment of deep brain abscesses by stereotactic implantation of an intracavitary device for evacuation and local application of antibiotic. Acta Neurochir (Wien) 1985; 76: 94-98.

4. Choudbury A, Taylor JC, Whitaker R. Primary excision of brain abscess. Br Med J 1977; 2: 1119-1121.

5. Rosenblum ML, Hoff JT, Norman D, Edwards MS, Berg BO. Nonoperative treatment of brain abscesses in selected high-risk patients. J Neurosurg 1980; 52: 217-225.

6. Barsoum AH, Lewis HC, Cannillo KL. Nonoperative treatment of multiple brain abscesses. Surg Neurol 1981; 16: 283-287.

7. Heineman HS, Braude AI, Osterholm JL. Intracranial suppurative disease: early presumptive diagnosis and successful treatment without surgery. JAMA 1971; 218: 1542-1547.

8. Young RF, Gade G, Grinnell V. Surgical treatment for fungal infections in the central nervous system. J Neurosurg 1985; 63: 371381 .

9. Bidzinski J, Koszewski W. The value of different methods of treatment of brain abscess in the CT era. Acta Neurochir 1990; 105: $117-120$.

10. Alderson D, Strong AJ, Ingham HR, Selkon JB. Fifteen-year review of the mortality of brain abscess. Neurosurgery 1981; 8: 1-6.

11. Bellar AJ, Sahar A, Praiss I. Brain Abscess. Review of 89 cases over a period of 30 years. J Neurol Neurosurg Psychiatry 1973; 36: 757-768.

12. Brewer NS, MacCarty CS, Wellman WE. Brain abscess: a review of recent experience. Ann Intern Med 1975; 82: 571-576.

13. Garfield J. Management of supratentorial intracranial abscess: a review of 200 cases. Br Med J 1969; 2: 7-11.

14. Van Alphen HAM, Dreissen JJR. Brain abscess and subdural empyema: factors influencing mortality and results of various surgical techniques. J Neurol Neurosurg Psychiatry 1976; 39 : 481-490.

15. Rosenblum ML, Hoff JT, Norman D, Weinstein PR, Pitts LH. Decreased mortality from brain abscess since advent of computerized tomography. J Neurosurg 1978; 49: 658-668.
16. Rajshekhar V, Chandy MJ. Successful stereotactic management of a large cardiogenic brain stem abscess. J Neurosurg 1994; 34: 368371.

17. Apuzzo MLJ. Brain Surgery: Complication, Avoidance and Management. New York: Churchill Livingstone, 1993; 2: 1411-1416.

18. Suwanwela C, Poshyachinda V, Poshyachinda M. Brain scanning in the diagnosis of intracranial abscess. Acta Neurochir 1971;25: $165-175$

19. Stevens EA, Norman D, Kramer RA, Messina AB, Newton TH Computed tomographic brain scanning in intraparenchymal pyogenic abscesses. Am J Neuroradiol 1978; 130: 111-114.

20. Whelan MA, Hilal SK. Computed tomography as a guide in the diagnosis and follow-up of brain abscesses. Radiology 1980 135: 663-671.

21. Berg B, Franklin G, Cuneo R, Boldrey E, Strimling B. Nonsurgical cure of brain abscess: early diagnosis and follow up with computerized tomography. Ann Neurol 1978; 3: 474-478.

22. Nielsen H, Gyldensted C, Harmsen A. Cerebral abscess: aetiology and pathogenesis, symptoms, diagnosis, and treatment. A review of 200 cases from 1935-1976. Acta Neurol Scand 1982; 65: 609. 622.

23. Newton TH, Norman D, Alvord EC, Shaw CM. The CT scan in infectious diseases of the CNS. In: Norman D, Korobkin M, Newton TH, eds. Computed Tomography. San Francisco: University of California Press, 1977; 317-338.

24. de Louvois J, Gortvai P, Hurley R. Bacteriology of abscesses of the central nervous system: a multicentre prospective study. $\mathrm{Br}$ Med J 1977; 2: 981-984.

25. Patrick CC, Kaplan SL. Current concept in the pathogenesis and management of brain abscesses in children. Pediatr Clin N Am 1988; 35: 625-636.

26. Everett ED, Strausbaugh LJ. Antimicrobial agents and the central nervous system. Neurosurgery 1980; 6: 691-714.

27. de Louvois $J$. The bacteriology and chemotherapy of brain abscess. J Antimicrob Chemother 1978; 4: 395-413.

28. Black P, Graybill JR, Charache P. Penetration of brain abscess by systemically administered antibiotics. J Neurosurg 1973; 38: 705-709.

29. Berger MS. Ultrasound-guided stereotaxtic biopsy using a new apparatus. J Neurosurg 1986; 65: 550-554.

30. Mundinger F, Birg W, Klar M. Computer-assisted stereotactic brain operations by means including computerized axial tomography. Appl Neurophysiol 1978; 41: 169-182.

31. Borgstein RL, Moxon RA, Hately W, et al. Preliminary experience with the Berger neurobiopsy device for ultrasound guided aspiration and biopsy of intracranial lesions. Clin Radiol 1991; 44: 98 103

32. Hollander D, Villemure JG, Leblanc R. Thalamic abscess: a stererotactically treatable lesion. J App Neurophysiol 1987; 50: 168-171.

33. Laborde G, Klimek L, Harders A, Gilsbach J. Frameless stereotactic drainage of intracranial abscesses. Surg Neurol 1993; 40: 16-21.

34. Lunsford LD, Nelson PB. Stereotactic aspiration of a brain abscess using the "therapeutic" CT scanner: a case report. Acta Neurochir (Wien) 1982; 62: 25-29.

35. Wise BL, Gleason CA. CT-directed stereotactic surgery in the management of brain abscess. Ann Neurol 1979; 6: 457.

36. Quartey GRC, Johnston JA, Rozdilsky B. Decadron in the treatment of cerebral abscess: an experimental study. J Neurosurg 1976; 45: 301-310.

37. Black KL, Farhat SM. Cerebral abscess: loss of computed tomographic enhancement with steroids. Case report. Neurosurgery 1984; 14: 215-217.

38. Mathisen GE. Brain Abscess. Conn's Current Therapy 1995, Edited by Robert E. Rakel, W. B. Saunders Company, Philadelphia $1995 ; 788-790$

39. Stapleton SR, Bell BA, Uttley D. Stereotactic aspiration of brain abscesses is the treatment of choice? Acta Neurochiralgica 1993; 121: 15-19.

40. Bucci MN, Carr WA. Stereotactic neurosurgery in the management of deep lesions in the brain. J S C Med Assoc 1991; 87: 5-7.

41. Walsh PR, Larson SJ, Rytel MW, Maiman DJ. Stereotactic aspiration of deep cerebral abscesses after CT-directed labeling. Appl Neurophysiol 1980; 43: 205-209. 
42. Gleason CA, Wise BL, Feinstein B. Stereotactic localization (with computerized tomographic scanning), biopsy, and radiofrequency treatment of deep brain lesions. Neurosurgery 1978; 2 : 217-222.

43. Dandy WE. Treatment of chronic abscess of the brain by tapping: preliminary note. JAMA 1926; 87: 1477-1478.

44. Kala M, Houdek M. Opening of the ventricular system: a potential preoperative complication of total brain abscess extirpation. Acta Univ Palacki Olomuc Fac Med 1990; 128: 123-126.

45. Dyste GN, Hitchon PW, Menezes AH, Vangilder JC, Green GM. Stereotaxic surgery in the treatment of multiple brain abscesses. J Neurosurg 1988; 69: 188-194.

46. Duma CM, Kondziolka D, Lunsford LD. Image-guided stereotactic management of non-AIDS related cerebral infection. Neurosurg Clin N Am 1992; 3: 291-302.
47. Itakura T, Yokote H, Ozaki F, et al. Stereotactic operation for brain abscess. Surg Neurol 1987; 28: 196-200.

48. Hall WA, Martinez AJ, Dummer JS, Lunsford LD. Nocardial brain abscess: diagnostic and therapeutic use of stereotactic aspiration. Surg Neurol 1987; 28: 114-118.

49. Goodman ML, Coffey RJ. Stereotactic drainage of aspergillus brain abscess with long-term survival: case report and review. Neurosurgery 1989; 24: 96-99.

50. Hasdemir MG, Ebeling U. CT-guided stereotactic aspiration and treatment of brain abscesses. An experience with 24 cases. Acta Neurochir (Wien) 1993; 125: 58-63. 